\title{
Escultura de morar
}

Sculpture of living

\section{Milton Machado ${ }^{1}$}

\footnotetext{
${ }^{1}$ Graduação em Arquitetura pela Faculdade de Arquitetura e Urbanismo da Universidade Federal do Rio de Janeiro (1970). Mestrado em planejamento urbano pelo Instituto de Pesquisa e Planejamento Urbano e Regional (1985). Doutorado em artes visuais - Phd Fine Arts, Goldsmiths College University Of London (2000). Professor titular da Escola de Belas Artes Universidade Federal Rio de Janeiro, no Departamento de História e Teoria da Arte e no Programa de Pós-graduação em Artes Visuais PPGAV-EBA. Artista plástico e pesquisador, com experiência na área de Artes, com ênfase em Teoria, Filosofia e Prática de Artes, com diversas exposições individuais e coletivas no Brasil e no exterior, diversos textos publicados em meios impressos e online, e comunicações em palestras e conferências.

Currículo lattes: http://lattes.cnpq.br/5338281816028562

E-mail: miltonmachado@terra.com.br.
} 


\title{
Resumo
}

Memórias e anotações sobre a experiência do autor como professor da cadeira de Projeto 1, para estudantes de primeiro período do curso de arquitetura do Centro de Arquitetura e Artes da Universidade Santa Úrsula, Rio de Janeiro. Atuando como professor das cadeiras de Plástica 1, 2 e 3 (Departamento de Análise e Representação da Forma) de 1979 a 1994, em 1993 o autor aceitou o convite - e o desafio - de elaborar um novo programa para a disciplina de Projeto 1, com resultados inesperados, surpreendentes, de altíssima qualidade, em se tratando de trabalhos de futuros arquitetos iniciantes. Referências a pesquisas de artistas e arquitetos precursores, tais como Kazimir Malevich e Buckminster Fuller.

\section{Palavras-chave}

Experimentalismo; Estruturas; Escultura; Arquitetura; Desenho e Design.

Disciplina de Projeto 1. Centro de Arquitetura e Artes, USU, Rio de Janeiro, 1993.

\begin{abstract}
Memories and records of the author's teaching experience proposing a new program for the discipline of Project 1, for students attending the first period of the architecture course at Centro de Arquitetura e Artes da Universidade Santa Úrsula, Rio de Janeiro. Teaching the disciplines of Plástica 1, 2 and 3 [Analysis and Representation of Form Department], in 1993 the author accepted the invitation - and the challenge - to elaborate a new program for the discipline of Project 1, with unexpected, surprisingly high-quality results, produced by initiating future architects. References are made to precursory research and practices of artists and architects, such as Kazimir Malevich and Buckminster Fuller.
\end{abstract}

\section{Keywords}

Experimentalism; Structures.; Sculpture; Architecture; Drawing and Design.

Project 1. Center for Architecture and Arts, USU, Rio de Janeiro, 1993. 
Em 1979, fui convidado por Lygia Pape a integrar o corpo docente do Centro de Arquitetura e Artes da Universidade Santa Úrsula, no Rio de Janeiro. A maioria dos professores do CAA-USU era formada por arquitetos. Lygia, artista e professora, não era arquiteta, mas uma singular e brilhante "pensadora do espaço", como demonstra o radical experimentalismo de seu trabalho que, entre outras honrosas atribuições, levou-a ao cargo de regente da cadeira de Plástica, disciplina que me coube ministrar. Costumo definir minha condição como a de um "arquiteto-sem-medidas", o que deve ter influenciado minha anfitriã, conhecedora de meu trabalho, quando decidiu convidar-me.

O Centro de Arquitetura e Artes da USU era uma das melhores faculdades de arquitetura do Rio, quiçá do Brasil. A atuação de Lygia foi fundamental para esse sucesso, e a cadeira de Plástica, sob sua regência (coube a mim o privilégio e a responsabilidade de sucedê-la no cargo), influenciou o projeto geral de ensino de arquitetura do CAA, voltado para a pesquisa, o estudo e a produção do espaço como lugar de experimentação. Sintoma dessa ênfase na crítica e na investigação conceitual é o número de artistas plásticos que passaram pelo Centro, muitos dos quais arquitetos graduados. Já contei - nos dedos, não é oficial - cerca de 48 artistas ex-alunos, muitos deles consagrados, atuantes no circuito profissional de artes. Tunga e Nelson Felix foram das primeiras turmas. Este último foi meu colega como professor no CAA.

Lecionei as disciplinas de Plástica 1, 2 e 3, de 1979 a 1994, quando me transferi para a Inglaterra para estudos de doutorado. Em 2002, ano seguinte a minha volta ao Brasil, concorri a uma vaga de professor adjunto na Escola de Belas Artes da UFRJ, onde atualmente sou professor titular no Departamento de História e Teoria da Arte. Exercício tentador seria buscar, em minhas aulas de história da arte, traços do experimentalismo que estou a enfatizar, aprendidos e treinados durante minha atuação no CAA-USU. São inúmeros. Afinal, este professor que aqui escreve é um artista e - agravante, repito - um "arquiteto-sem-medidas". O que, de certa forma, dá no mesmo.

Mas devo falar aqui de outra experiência, igualmente rica e reveladora, no mesmo ambiente. Em 1993, o então decano do CAA pediu-me que elaborasse um novo programa da disciplina de PROJETO 1 (sempre impliquei e implico com o termo "disciplina", que tem algo de militarista, ainda mais quando as ênfases são o experimental e o desmedido). É dessa experiência que vou tratar neste texto.

PROJETO 1 - era o primeiro contato de nossos estudantes com a prática projetual. E com alguma teoria. Em alguns casos, era quando "o bom arquiteto / a boa arquiteta" de futuro demonstrava sua vocação. Embora se diga que aqueles brinquedos de bloquinhos coloridos de madeira, com telhados, janelas, portas, arcos, pontes e outros elementos construtivos - arquitetônicos? - constituem a verdadeira iniciação. Chamava-se, chama-se ainda, O Pequeno Arquiteto. Um clássico. Coloquei Pequeno Arquiteto no browser, fui levado a diversas opções de compra por internet.

O programa que elaborei, com o apoio de colegas arquitetos professores, tinha 
também algo de lúdico, de joguete de criança. Passo a descrever o exercício, que ocupou a turma durante todo o período. No fundo, o exercício constituía - para além da manualidade, da artesania, do fazer e da prática - uma reflexão sobre processos criativos, sobre noções de representação, sobre o simbólico, sobre a relativa insuficiência dos modelos, sobre a instabilidade dos significados, sobre funcionalidade, sobre desenho, sobre escultura, sobre forma e conteúdo, sobre plasticidade, ornamento, estrutura etc. No limite, sobre arquitetura. Em questão: o espaço. $\bigcirc$ exercício se dava em seis fases.

\section{Primeira fase:}

A primeira encomenda era que produzissem desenhos livres. Individuais, feitos em casa. Em sua maioria, os desenhos que apresentaram eram surpreendentemente rudimentares e infantis - daquelas recorrentes paisagens de casinhas com uma porta no centro e duas janelinhas laterais, fumaça saindo de chaminés, árvores pintadas a lápis de cor verde com um tronco marrom e redondas maçãs vermelhas brotando das copas, um sol radiante com dois olhos e uma boca sorridente sobre um fundo azul celeste. Algumas nuvens...

Mostrei-os para os professores de Desenho, desafiando-os a adivinhar a idade dos autores. "Algo entre 8 e 10 anos", arriscaram. A primeira lição que aprendemos foi, portanto, que o desenho espontâneo e autoral de nossos alunos não correspondia aos exercícios dirigidos praticados na disciplina. Lembro que a constatação causou espécie, e ensejou uma tentativa de reformulação do programa de Desenho. Desenho Artístico, para ser exato, era o nome da disciplina. Mas a "qualidade" (artística) dos desenhos não importava para nosso exercício de iniciação ao projeto.

Levei um pão de forma cortado em fatias, de modo a fazê-los entender o que vem a ser uma seção. Pedi que considerassem seus desenhos como uma seção de algum objeto tridimensional, que poderia brotar (como as maçãs de suas árvores e os raios de seus sóis) para ambos os lados do plano do papel e em diversas direções, ortogonalmente ou em ângulo.

\section{Segunda fase:}

Os desenhos feitos em casa, via de regra precários, foram então retrabalhados e elaborados em sala de aula, com orientação de professores, resultando uma produção gráfica intensa, numerosa, variada, promissora de interessantes desenvolvimentos nas próximas fases do exercício.

Nesta segunda fase, os inúmeros desenhos de estudos, agora elaborados, produzidos a partir de seus problemáticos originais caseiros já não tinham nada de infantis; afinal, eram desenhos de futuros (bons) arquitetos e arquitetas. As nuvens deram lugar à claridade. Os desenhos deram lugar ao Desenho.

\section{Terceira fase:}

A terceira fase consistia em confeccionar modelos em cartão branco - planos de massa - de modo a enfatizar relações entre volumes, sem atenção a detalhes. Modelos tridimensionais construídos - enfatizo a palavra construção - a partir dos desenhos já elaborados na fase anterior. Dos vários planos de massa produzidos, 
um era selecionado para desenvolvimento (ver, abaixo, referências aos Arkhitektons, modelos de gesso - e aos desenhos, os chamados planits - produzidos por Kasimir Malevich com sua turma de jovens alunos secundaristas).

\section{Quarta fase:}

Nesta fase, a ênfase era na estrutura. A partir dos planos de massa de cartão branco, foram construídos outros modelos, desta vez com varetas e pranchas de madeira de balsa, de modo a revelar as estruturas internas dos modelos em papel. As imagens que reproduzo aqui são fotos desses modelos estruturais, desenvolvidos nessa quarta fase. É pena que as próximas fases do exercício, com aplicação de revestimentos, vedações etc., tenham implicado na invisibilidade (parcial) dessas belas estruturas. Nesse momento de transição, registros fotográficos tornaram-se fundamentais. As fotografias, nesse momento, são mais do que imagens do que foi: numa metáfora economicista, revelam, digamos assim, a "alma do negócio".
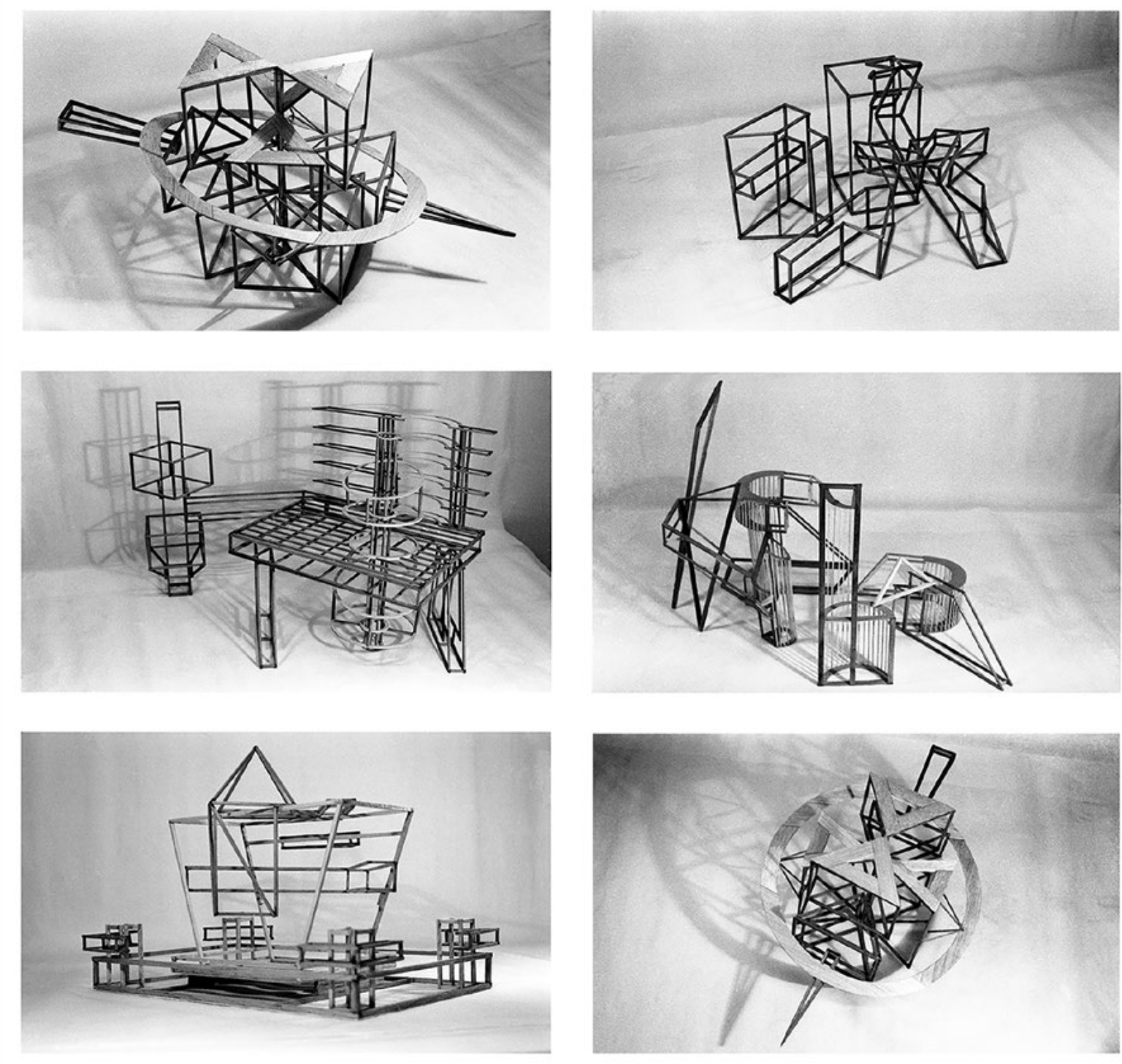


\section{Quinta fase:}

Esses modelos estruturais foram então recobertos com superfícies de vedação e revestimento. Nesta fase, introduzia-se cor, texturas, relevos, aberturas, entre outros detalhes de acabamento, externos e internos. Aos poucos, aqueles modelos inicialmente inanimados foram se transformando em criaturas vivas, vibrantes, excitantes e excitadas, postas em movimento. Aos poucos se vislumbrava, já aí, promessas de alguma arquitetura. Uma arquitetura não necessariamente com medidas.

\section{Sexta fase:}

Os modelos foram então "habitados", por todo tipo de ocupante: coisas, fenômenos, volumes, correntes de ar, tubulações, água, luzes, brilhos, sons, ruídos, música, elementos móveis, energias, vibrações, tremores, climas etc. Mesmo por ausências, vazios, silêncios, pausas, repousos. Somente nesta última fase deveriam os alunos indicar eventuais vocações funcionais - arquitetônicas? - para seus objetos. Mas isso era uma preocupação menor e um objetivo secundário: a proposta principal era de ativar uma pesquisa fundamentalmente plástica, quase escultórica.

Nesta fase final, a fotografia mais uma vez exercia papel fundamental, não apenas como documentação, mas como material originador de novas pesquisas, a partir da imagem. Os estudantes foram então encorajados a produzir abundantes registros fotográficos, dos quais surgiram ideias para novos espaços, novos projetos.

\section{O teste:}

Fiz questão de trazer alunos dos últimos períodos, prestes portanto a se formarem, para verem os objetos, que coloquei em exposição. As fotos referidas acima foram incluídas. Ficou com jeito de exposição do grupo Obmokhu (Moscou, maio de 1921), onde brilharam, ao lado de outras obras igualmente geniais dos construtivistas russos, os trabalhos de Karl loganson, precursor das pesquisas mais tarde levadas a cabo nos Estados Unidos por Buckminster Fuller, em torno das estruturas conhecidas como tensegrity, termo cunhado por Fuller a partir dos termos "integral tension" (tensão integral). Os modelos de meus jovens e iniciantes alunos teriam feito bonito na companhia dos construtivistas russos e das estruturas geodésicas depois exploradas por Buckminster Fuller. Oportuno lembrar que Fuller desenvolveu seus estudos de tensão integral na companhia de alunos.

Por certo fariam bonito, os veteranos quase arquitetos que o digam. Diante daquelas "coisas", daqueles objetos não-identificados (teriam a ver com os Bichos de Lygia Clark, com os Contra-Relevos de Tatlin, com a Construção Oval Pendente de Rodchenko, com os Relevos Espaciais de Helio Oiticica?), apostaram que só podia tratar-se de trabalhos de arquitetos famosos - Eisenman, Gehry, Calatrava, Foster, Hadid... Custaram a acreditar que seus autores eram estudantes de primeiro período. Mas, como eu, acreditaram. 
Exposição Obmokhu, Moscou 1921 Karl loganson Tumbir
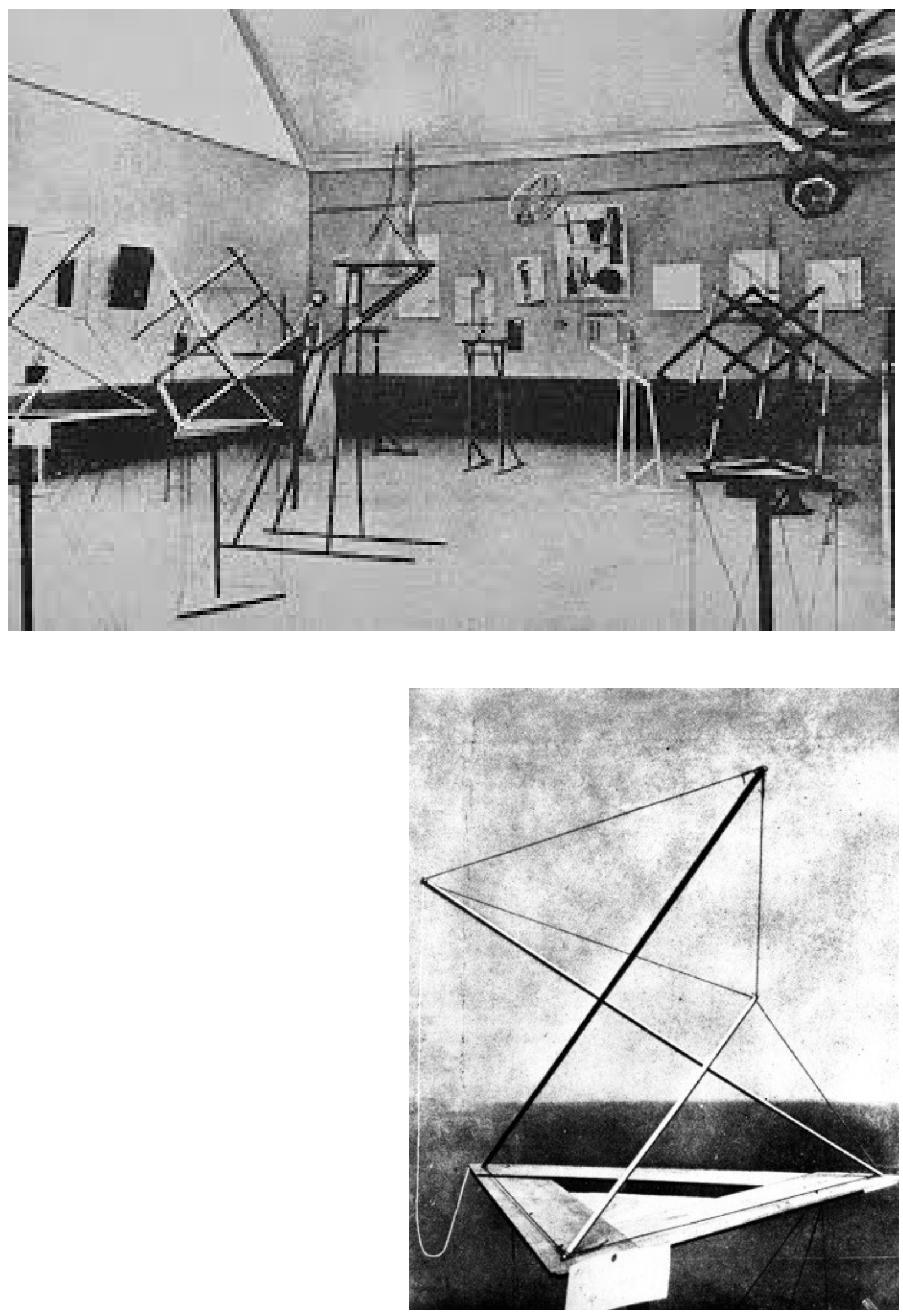

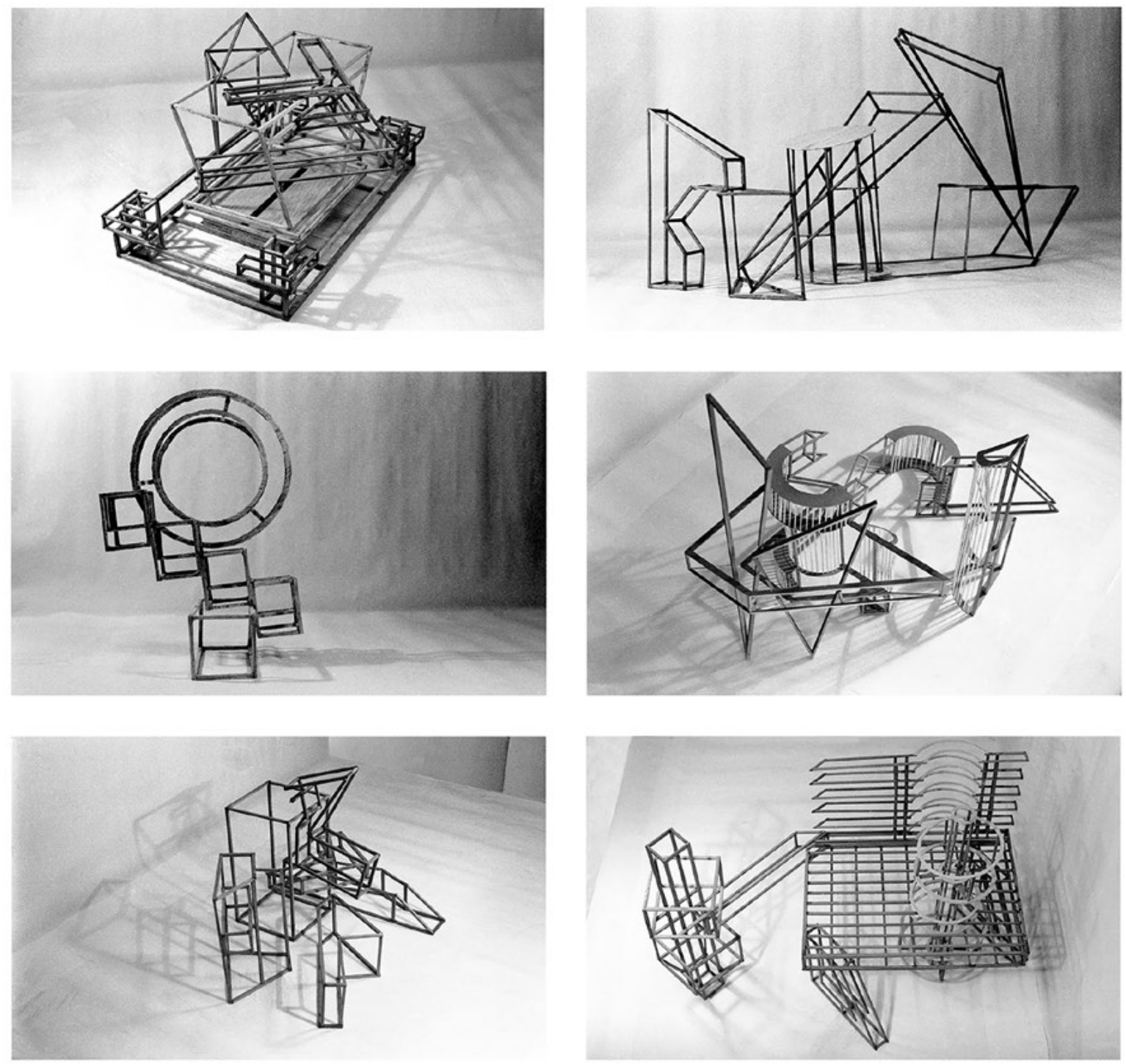

\section{Um recado para meus ex-alunos da turma de 1993:}

Seus nomes perderam-se em minhas gavetas de memórias. Afinal, 27 anos se passaram desde nosso memorável e produtivo encontro com a experimentação. Se algum desses arquitetos, hoje com idades entre 45 e 50 anos, reconhecer esses belos objetos como produtos de sua autoria, favor identificar-se.

\section{Kasimir Malevich: arkhitektons, planits}

De 1923 a inícios da década de 1930, o artista russo Kasimir Malevich produziu diversos modelos tridimensionais, formas abstratas similares a arranha-céus, chamados arkhitektons. Os desenhos de acompanhamento da construção desses modelos são chamados planits. A experiência foi desenvolvida com seus jovens alunos do curso secundário. 
Os arkhitektons são basicamente modelos feitos em gesso branco, compostos por diversos blocos retangulares agregados. Eram estudos puramente experimentais, e os "edifícios" eram desprovidos de qualquer organização interna. São, aqui também, "planos de massa". Também não pretendiam a condição de artefatos funcionais, com vocações propriamente arquitetônicas. As formas finais resultantes da reunião das massas individuais eram função da pesquisa plástica, escultórica. Nesse sentido, constituíam "abstrações espacializadas", tridimensionais, não-objetivas, relacionadas às pesquisas desenvolvidas pelo artista no campo da pintura, segundo princípios suprematistas de composição.

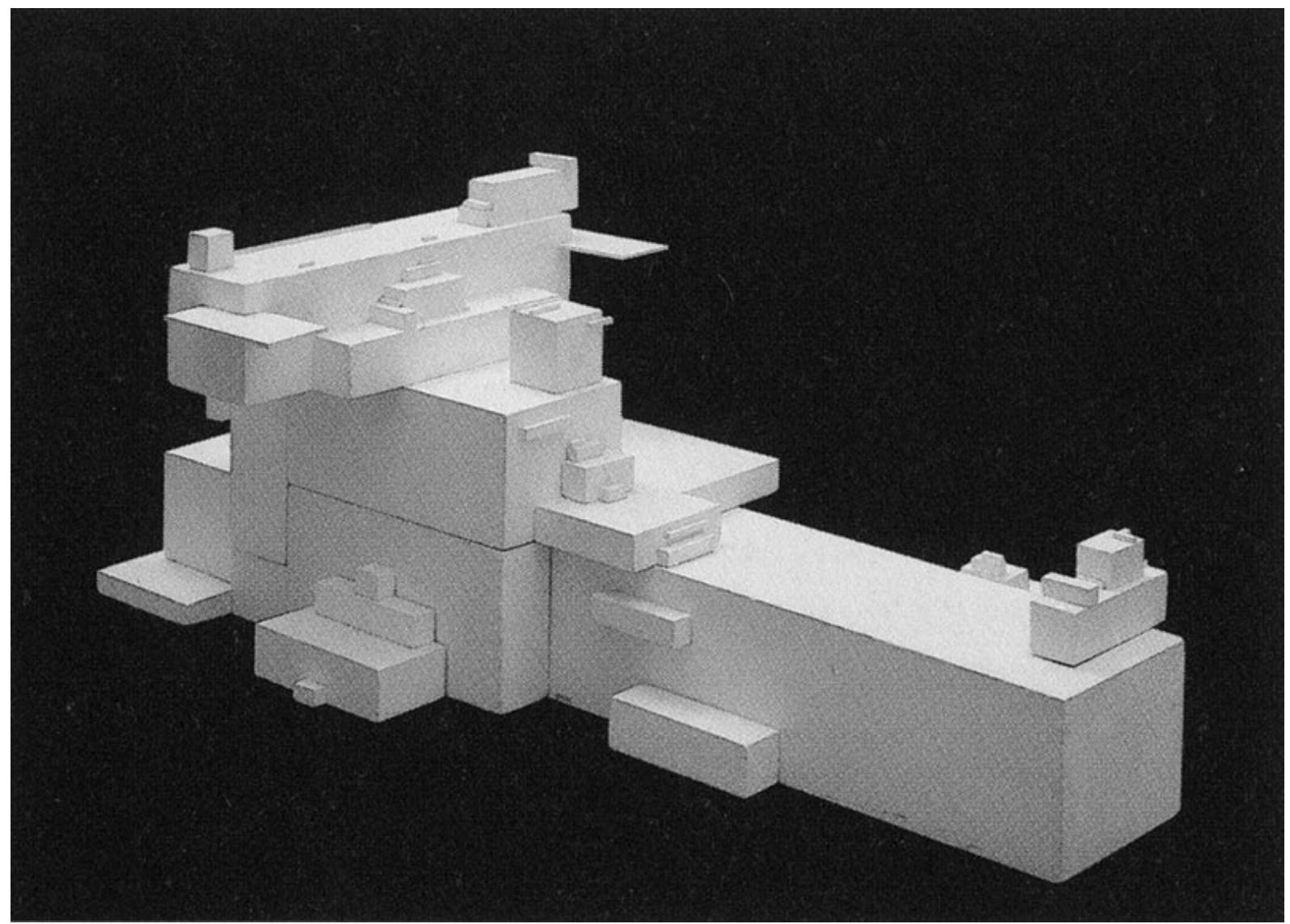




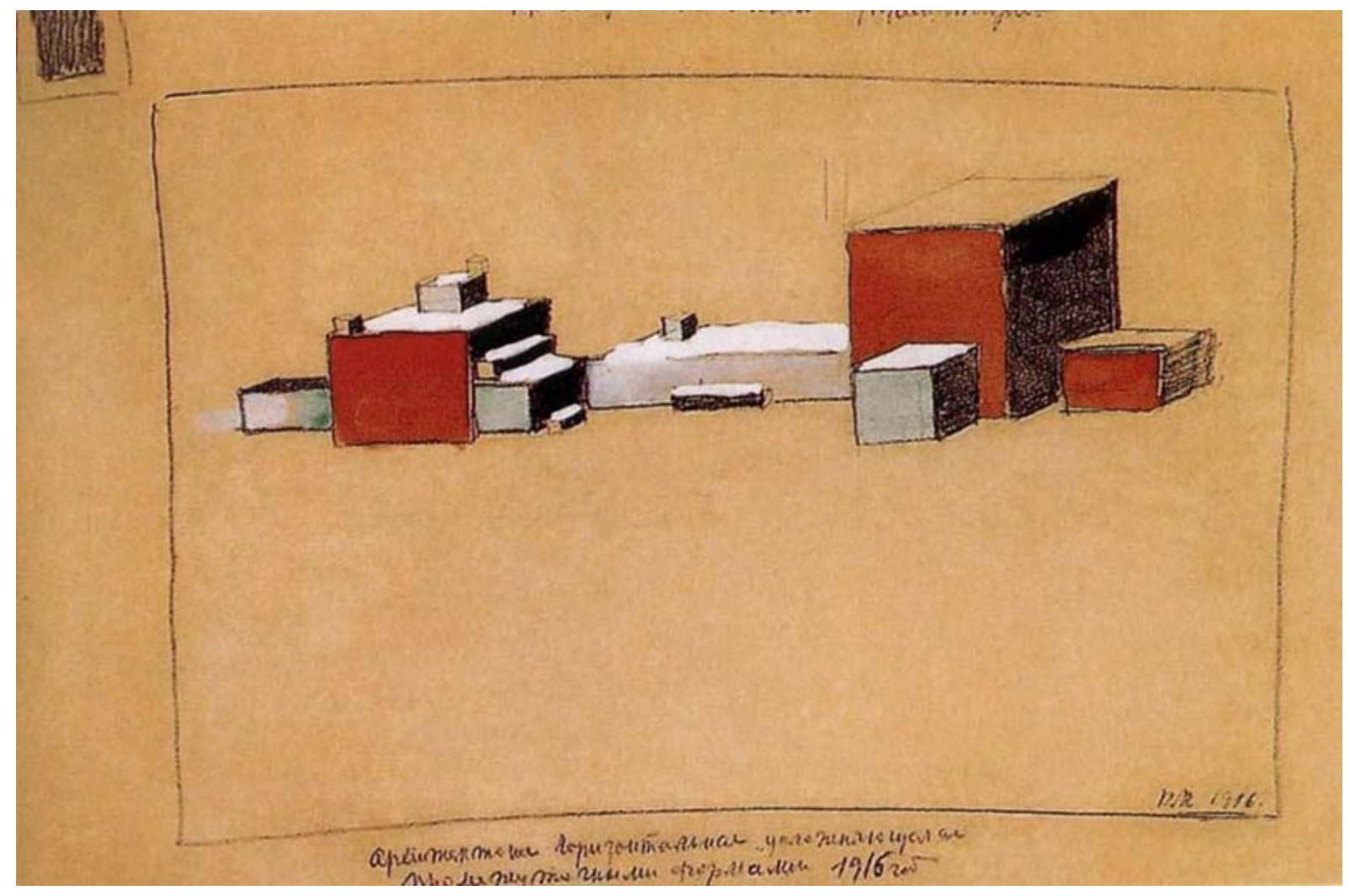

Malevich Arkhitekton / Planit

Qualquer semelhança não terá sido mera coincidência.

Recebido em 08 de junho de 2020.

Aprovado em 15 de julho de 2020. 